\title{
Effect of Station Improvement Measures on Customer
}

\section{Satisfaction}

\author{
Mark van Hagen \\ Research and Development Department, Netherlands Railways, Utrecht 3500HA, the Netherlands
}

\begin{abstract}
Stations are often regarded as change engines-places where passengers have to change as quickly and efficiently as possible from one mode of transport to another. Underpinned by research, NS (Netherlands Railways) currently takes the view that stations should be transformed into dynamic urban portals that not only facilitate a speedy transfer but also make the stay at the station more enjoyable. To discover which aspects the customer perceives as important, NS developed a research method that is based on environmental psychology and with which the impact of passengers' waiting and station experience can be measured. This article addresses the measures taken, the method of measurement and the measurement results. Examples of such measures are: experimenting with colour, light, music, infotainment and increasing and repositioning the shopping facilities. Our studies not only showed an increase in the score for the general evaluation of a test station (Leiden Central Station) with one full point but also significant positive effects on various aspects of waiting and experience.
\end{abstract}

Key words: Waiting, experience, station, satisfiers, satisfaction, standard measurement instrument.

\section{Introduction}

The focus of NS (Netherlands Railways) is to prioritize the quality improvement in such a way that "the customer comes at the first, the second and the third place". So the needs of the customers are a pivotal point in enhancing the quality of a train journey including the use of the stations. In order to create appealing stations, it is imperative that we ascertain what passengers actually find appealing and which aspects are of importance. For passengers, stations are important links in their journey. On average, passengers spend $7 \mathrm{~min}$ at a station $[1,2]$, and stations determine circa $25 \%$ of the score awarded to the total train journey [3]. It is also apparent that the stay at the station is valued twice to three times lower than the stay on the train $[4,5]$. Overestimation of waiting time is greatest on the platforms $[1,2]$. Improving the quality experience of stations thus has a large impact on the satisfaction with the train journey. To find out which measures really enhance the quality

Corresponding author: Mark van Hagen, Dr., research fields: transport and behavioural sciences. E-mail: mark.vanhagen@ns.nl. according to the passengers, NS chose one test station with the purpose to discover which measures work best. Leiden Central Station was chosen as the location for testing new experience-related measures, based on passenger requirements. Over 3 years, NS and ProRail have conducted various experiments, both in real life and in a virtual laboratory, and taken measures to improve the stay at the station.

\section{From Change Engine to Dynamic City Portal}

Until recently, stations were predominantly regarded as change engines, where passengers can change as quickly and as efficiently as possible from one mode of transport to another. The current view of NS is to transform the stations into dynamic town portals that not only facilitate a quick transfer but also make the stay at the station more pleasant [6]. With dozens of large stations up for renovation in the coming years, this will afford a chance to give them a quality impulse whereby much attention will not only be paid to increasing utility but also improving the experiential value of the stations. For a successful 
improvement of the latter, it must be clear how passengers experience the station and what their requirements are. We will thus first address the wishes and needs of customers, after which we will discuss the test station case at Leiden, where various measures were taken to improve experiential value. The effects of these measures on the experience of station visitors were measured with the station experience monitor, an experience instrument developed by the department NS MRA (Market Research and Advice). After presenting the results, several conclusions and recommendations can be drawn.

\section{Customer Needs at a Station}

NS MRA has designed a pyramid of customer needs (Fig. 1) that reflects the perception of the quality offered by NS [7, 8].

Analogous to Maslow's hierarchy, the various needs of customers can be ranked according to importance in the shape of a pyramid $[8,9]$. The base of the pyramid is formed by the basic needs - reliability and safety. For passengers, safety particularly means social safety and this is a prerequisite for the functioning of a station as a public space. If potential customers perceive a station to be unsafe, they will avoid it. Reliability indicates the degree to which passengers experience receiving what they expect. If the service is not available when and where customers expect it, it will result in their being dissatisfied. As already ascertained, speed is the principal customer need, i.e., the majority of customers choose as short a travel time between origin and destination as possible. If the condition of a fast journey and transfer has been complied with, then the traveller wants the change to be easy, i.e., convenient and with little hassle. Travel information and signposting are a help and must be seen as logical and unambiguous. Also, the traveller expects a certain degree of physical comfort at the station: sheltered waiting and seating areas, and food and refreshment facilities. Finally, the need of a pleasant experience must be fulfilled and this is influenced by such visual

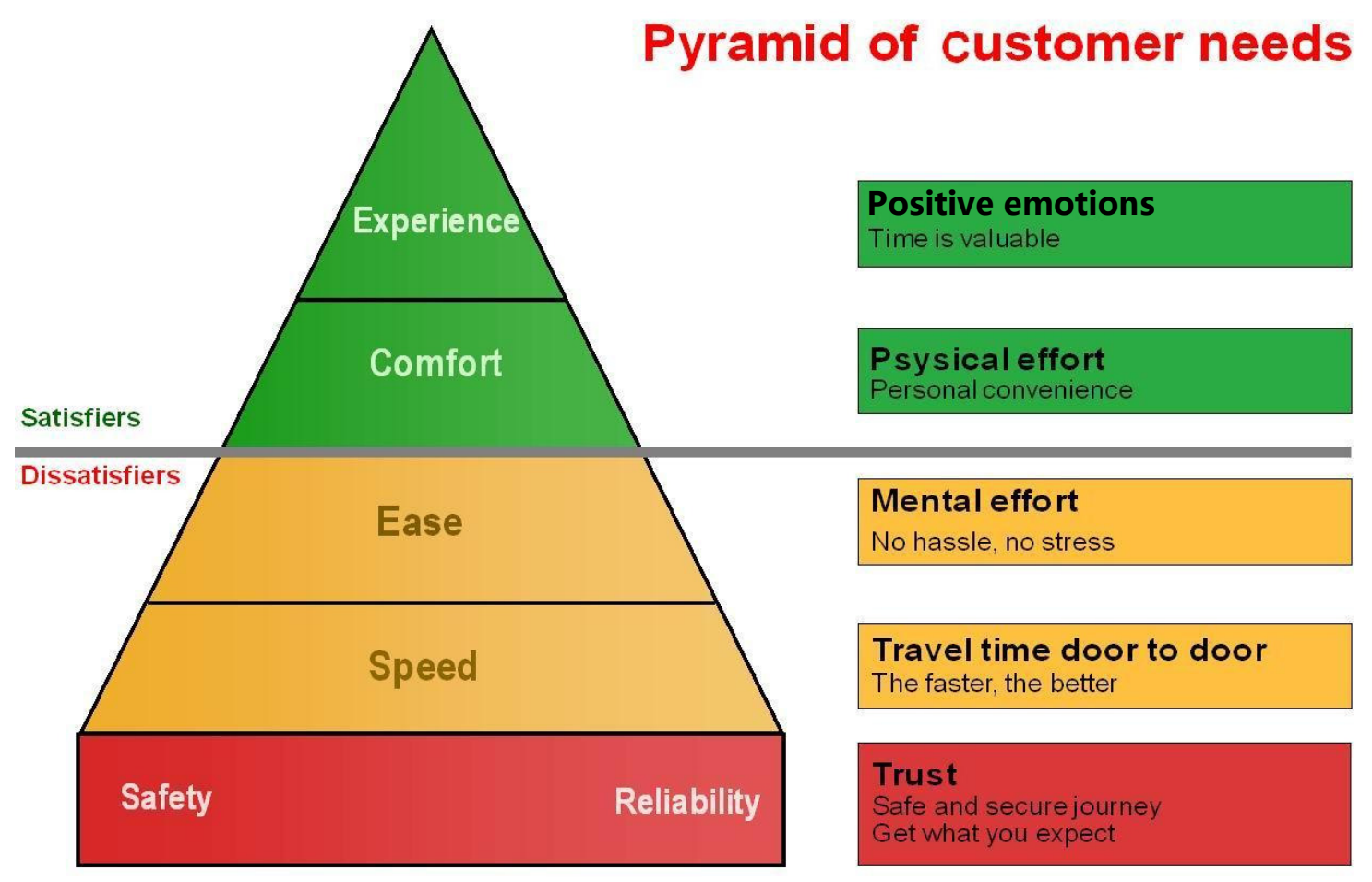

Fig. 1 Quality dimensions in order of importance. 
aspects as architecture, design, cleanliness, materials and colours used. Besides these, however, also less tangible environmental variables, such as (day) light, smell and music, influence the quality of experience. Offering facilities such as shops and cafes, and the obvious presence of staff enhance a pleasant stay. Fig. 1 shows the hierarchy in interests of the various quality dimensions $[8,10]$. The red and yellow qualities are basic functionalities and can be seen as dissatisfiers, while the green qualities can make customers happy and can be seen as satisfiers [11].

The passenger will experience a station as pleasant when each layer of the pyramid has been complied with. In the event of one of the layers being of inferior quality, it will affect the total evaluation of the station. Moreover, people primarily desire a sense of control before they can enjoy a pleasant waiting environment. This implies that the qualities at the base of the pyramid of customer needs must first be addressed before the qualities at the apex of the pyramid can be specifically improved. Also, it is of importance that when travellers move through the station, speed and ease are key, but when they have to stay at a station, like during a wait, then comfort and experience are vital $[12,13]$. In this respect, speed and ease are dissatisfiers in which these quality aspects are rated negatively if they do not meet expectation [11]. All passengers set great store by a safe, reliable, easy and speedy journey. Such dimensions are the bedrock of transportation, and they are generic and can be applied to each station. Comfort and experience are satisfiers $[11,14]$. They are noticed when the station is evaluated positively, albeit the interpretation can vary per passenger. Just as one passenger wishes to travel first class, eat sushi at a station and admire the architecture, so is another passenger content to travel second class, eat a rissole from a vending machine and only see the station as an efficient transfer space.

Various transport scientists employ such a pyramid of customer needs. The interest layers of this pyramid are supported by several qualitative and quantitative studies. With the stated preference approach $(N=800)$, for example, the order of importance of quality aspects for a train journey was shown to be the same as in the hierarchy of the pyramid of customer needs [10]. Also, factor analyses on different customer evaluations of train passengers $(N=480,000)[15]$ and public transport passengers $(N=85,000)[16,17]$ resulted in different quality dimensions, whereby the quality aspects at the base of the pyramid are more important than those higher up. On the basis of group interviews with customers, Preston et al. [18] ascertained that a "hierarchical pyramid of needs" also exists for stations. They concluded, "a hierarchical pyramid of needs was suggested, reinforcing the findings from the literature review. The base of the pyramid consists of basic factors, such as reliability and frequency of service and, at the apex, we find enhancing factors such as retail and catering facilities."

\section{Six Segments Needed}

The needs at the base of the pyramid (dissatisfiers) are generic and applied to all customers. Those at the apex are specific and customers can have different needs in the same place at the same time. The various needs at the apex have been elaborated on further with the needscope model $[19,20]$. This needscope model defines six types of passengers, each with its own package of related needs: the explorer, the individualist, the functional planner, the certainty seeker, the socializer and the convenience seeker (Fig. 2) [19].

\section{NS Vision of Stations and Test Station Leiden}

The vision of NS $[6,21,22]$ is to create town portals based on customer needs. On the basis of the needs stipulated in both the pyramid of customer needs and the needs coping segmentation. Research [1] showed that customer needs are influenced by motivational orientation and the amount of stimuli from 


\section{Six different needstates}

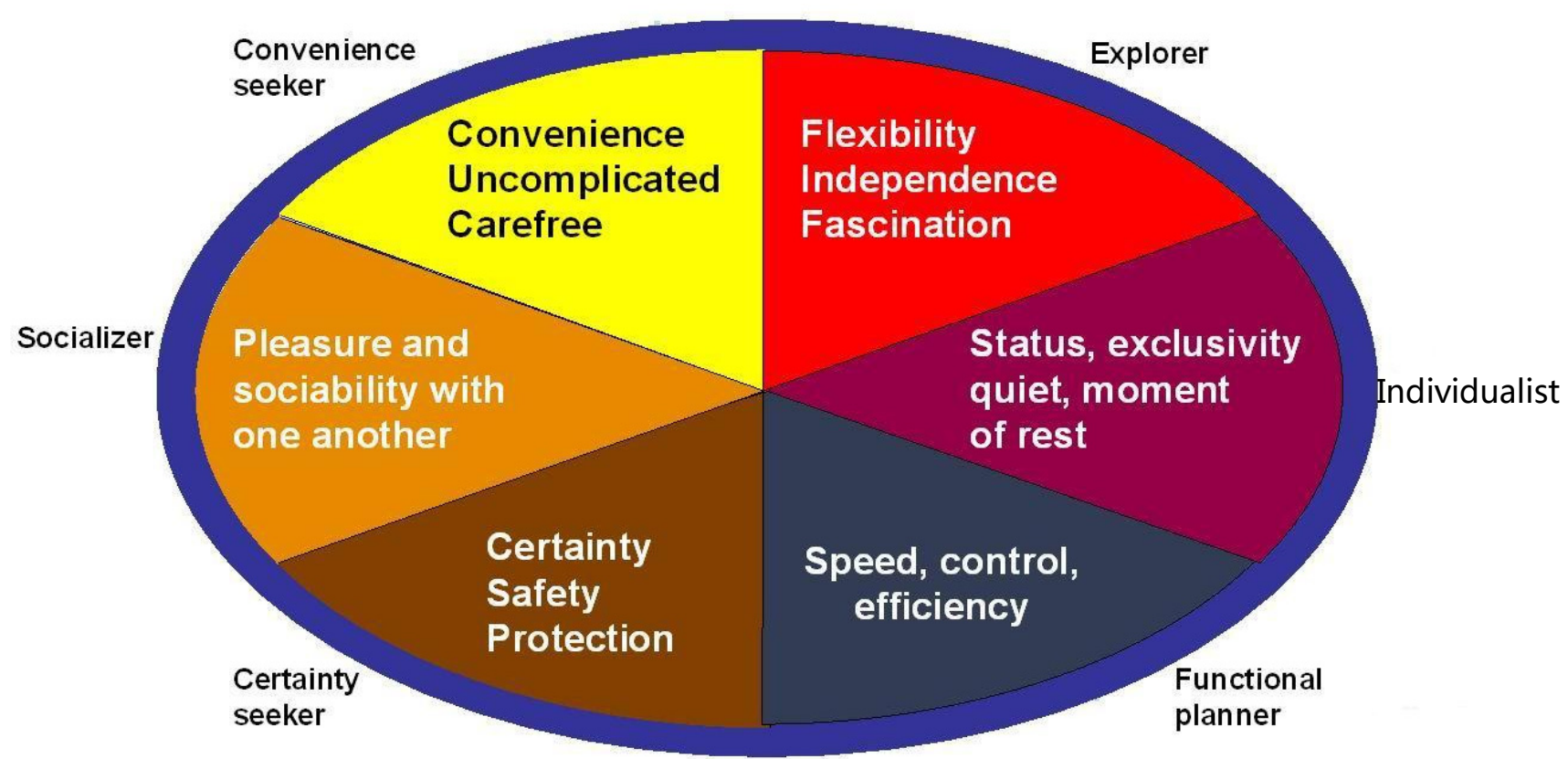

\section{Within the domain of train travel}

Fig. 2 The six need segments.

the environment. Customer needs vary from time to time and from place to place:

- Time. In rush hours, customers are less keen on extra environmental stimuli (like up tempo music or warm colors), because they will experience more stress in that way. But in off-peak hours, customers do want to get extra stimulation (and do like up tempo music or warm colors), otherwise they will get bored;

- Place. When passengers are moving (transfer area like stairs, escalators, corridors), they don't like to be stimulated too much and don't like any distraction. On the other hand, when passengers are staying somewhere, like waiting, they are fond of extra stimuli and distraction.

Based on these insights, various spatial domains have been distinguished within the station with similar functions clustered and anticipating the customer needs with an environment which offers little or high stimulation [23]. These domains are:

- arrival domain;

- reception domain;

- stay domain;

- travel domain.

This NS vision is being implemented at large stations where high speed trains will stop (Amsterdam, Rotterdam, Schiphol, the Hague, Utrecht, Breda and Arnhem). In order to locate the right functions in the correct place, Leiden was chosen as the test station, where various (experiential) measures were tried out and their effects measured. Leiden was chosen as it is the fifth largest station in the Netherlands and each type of passenger is well represented there. This meant that every need could be sufficiently tried and many measures tested. Within the various domains, sundry "worlds" can be created that address the needs of different passengers and station visitors according 
to time and place. As yet seven different worlds have been distinguished:

(1) Service world (reception domain). Here, all service facilities have been grouped together, such as tickets and service, currency exchange office, tourist information, dry cleaner, shoe service and a travel agency;

(2) Food world (stay domain). In a centrally situated food court, passengers and station visitors can eat and drink products bought from various surrounding shops. Examples include newly developed formulas such as Julia's (pasta to go) and Shakies (fresh fruit juices), but also existing chains such as Smullers, Starbucks and Burger King;

(3) Media world (stay domain). A national and international assortment of literature can be found in the media world but also daily, weekly and monthly newspapers and magazines, as well as a wide assortment of mobile media and digital technology, including DVDs, games and MP3s;

(4) Health and beauty world (stay domain). Here, we find not only a chemist with a large selection of care and self-medication products but also a relatively high-quality perfumery with luxury care products;

(5) Fashion world (stay domain). Trendy men and (particularly) women's wear, as well as accessories that can easily be carried on to the train and travel-related products such as bags, suitcases and travel accessories;

(6) Event world (stay domain). A special venue for entertainment, such as concerts, exhibitions or product installations with a unique appeal;

(7) To go world (travel domain). Walk-in formulas where people can quickly buy something to eat or drink to take home or to consume whilst en-route, such as coffee, snacks, etc..

\section{Procedure: Measure Try-Out at Test Station Leiden}

Since 2008, all kinds of measures have been taken at Leiden Station that address NS's vision. For example, various shops and amenities in the seven worlds have been clustered (e.g., food court, travel world) and pilot studies conducted on signing, flow (e.g., red footsteps that indicated to keep right on the escalator) and new platform furniture (e.g., modern designed furniture made of wood instead of steel). Also, it was investigated that how the atmosphere at the station could be improved such that it more closely met the needs of passengers at various times and in various locations within the station. Examples here are the placing of trees and heat columns and experimenting with infotainment, music, colour and light intensity on the platform [1]. In the station concourse, experiments were carried out with smell (stimulating versus relaxing) and new, spacious toilets were installed on the basis of co-creation (design competition). Former publications discussed the effects of separate measures, such as music (fast tempo music versus slow tempo music), infotainment (fast moving images versus slow moving images), colour (cool colours, like blue versus warm colours, like red) and light (high light intensity versus low light intensity) [1, 2, 12, 24-29]. The studies proved that passengers in rush hours or when moving want little stimulation form the environment and passengers in off-peak hours or when staying want much stimulation from the environment. This paper will present the results of all steps implemented at the station.

Before any steps were realised, a baseline measurement was taken at Leiden Station. In order to gain insight into the effects of the steps that were being taken, five further measurements were carried out (after the baseline measurement) with the measurement instrument "station experience monitor". Table 1 shows the moments when measurements took place at Leiden Central. In mid 2011, a year after completing the Leiden test station, the final so-called evaluation measurement was carried out to determine whether the realized improvements were still holding their own. 
Table 1 Measurement moments at Leiden Central Station.

\begin{tabular}{lll}
\hline & Fieldwork period & Sample $(n)$ \\
\hline Baseline measurement & November 29 December 8, 2008 & $n=650$ \\
1st measurement & December 20 December 28, 2008 & $n=280$ \\
2nd measurement & June 30 July 9, 2009 & $n=336$ \\
3rd measurement & December 16 December 21, 2009 & $n=344$ \\
4th measurement & June 25 July 6, 2010 & $n=306$ \\
5th measurement & May 4 May 20, 2011 & $n=399$ \\
\hline
\end{tabular}

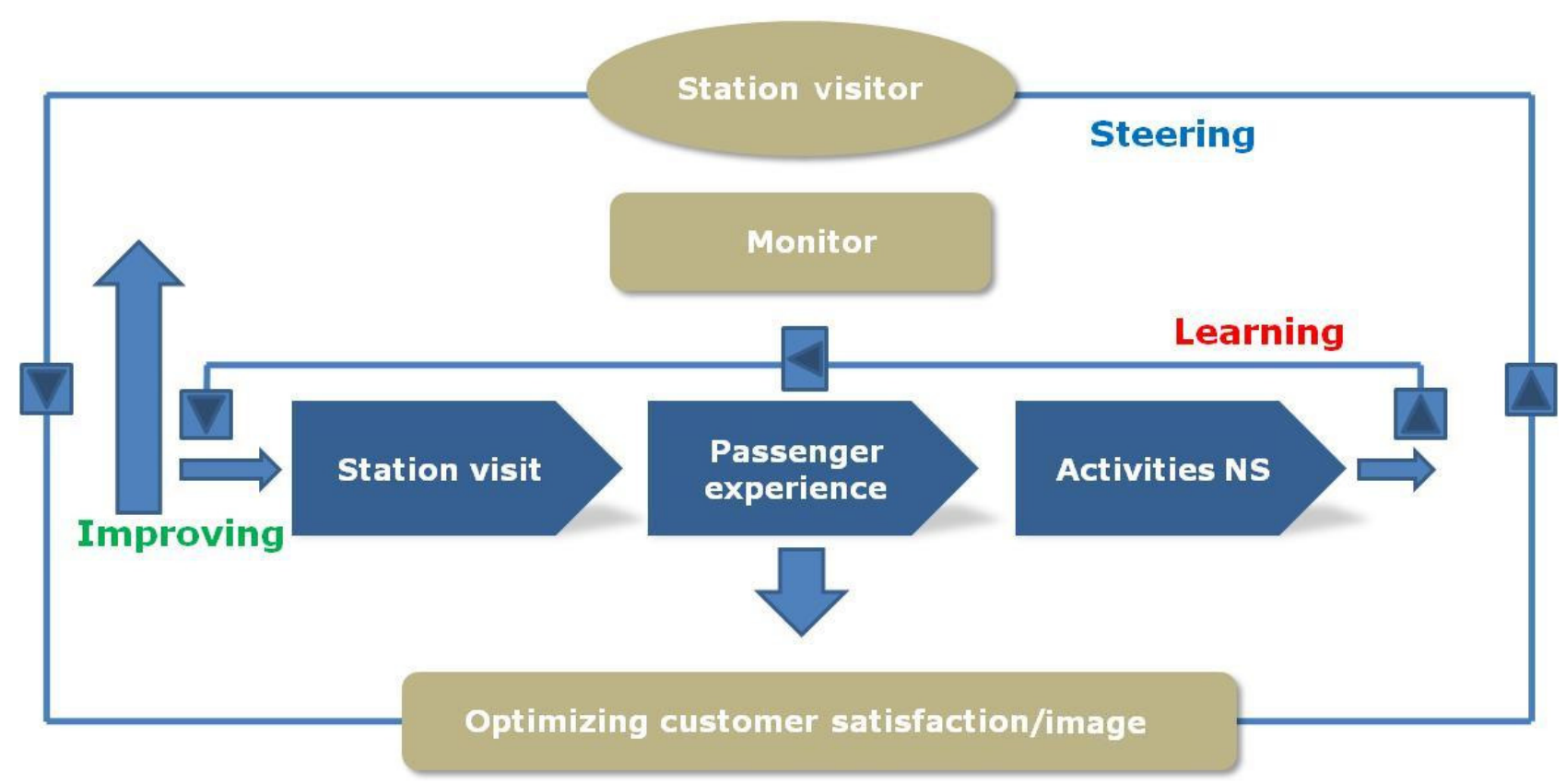

Fig. 3 Learning model passenger experience station.

\section{Method: Towards a Standard Experience Instrument}

It goes without saying that taking all kinds of different measures, such as at test station Leiden, should afford an insight into the impact such measures have on passenger experience. It is true that some measures have been measured before, but until recently, their "learning effect" was limited, because:

- New research was repeatedly initiated with a focus on the measure taken;

- The studies were primarily set up to determine dissatisfaction;

- No standard measures were conducted, which meant that comparability and much knowledge were lost (efficiency and effectiveness).

For NS, these limitations were the reason that a standard experience instrument should be developed. Important sources of inspiration were the learning model (Fig. 3), the intrinsic underpinning of which was drawn from the pyramid of customer needs and scientific insight into waiting experience [1, 19, 30].

When developing this instrument, the quality dimensions of the pyramid of customer needs were translated into items which, underpinned by scientific research, appear to have greatly influenced experience [31]. The publication "Naar een Standaard Belevings Instrument" (To a Standard Experience Instrument) by Van Hagen et al. [31] gave an exhaustive account of how this relationship is made.

Furthermore, interviews were conducted with various stakeholders of NS stations, NS retail and ProRail (the infrastructure provider), revealing extra items relevant to each stakeholder's directives, which 
were thus also included in the experience instrument. Finally, in consultation with the stakeholders and end-users of this new instrument, the decision was made to ask respondents for a clarification if scores were extremely high ( $>8$ on a 10-point scale) or extremely low ( $<5$ on a 10 -point scale). With these clarifications immediately offering ideas for improvement to the station management concerned, quality research into improving certain issues is hence not always necessary.

\section{Method: Station Experience Monitor}

The experience instrument consists of a short questionnaire to be filled in by waiting passengers on the platform. It addresses various aspects of the station experience, such as functional aspects, experiential aspects, general evaluations, result variables and background variables. The departure platform was chosen as the location because, having arrived there, passengers have seen the entire station and can pass judgement on it. On the platform, passengers moreover have the time and are more receptive to fill in a questionnaire. All questions and propositions are awarded a score from 1 to $10(1=$ very poor, $10=$ excellent). When respondents are unable to say anything about a certain item, the letters NA (non-applicable) is recorded. When passengers award an item with a 5 or lower or with an 8 or higher, they are asked to clarify their score.

\subsection{Customer Satisfaction Questions and Functional Aspects (Dissatisfiers)}

Functional aspects at the stations, such as safety, cleanliness, overview and flow, remain crucial to customers. In order to make the KPIs (key performance indicators) less general in the experience study, respondents were sometimes asked about the station, platform and bicycle point/parking facilities.

\subsection{Experiential Aspects (Satisfiers)}

As stated before, experiential aspects have a profound influence on customers' station evaluation and integral experience. Examples of experiential aspects included in the new experience instrument relate to the atmosphere (e.g., lighting, colourful, appealing) [21], the waiting experience (e.g., comfortable, useful, pleasant wait) and dimensions of emotion (pleasure, arousal and dominance) [28, 32].

\subsection{General Opinion and Result Variables}

Ultimately, the measures influence the general opinion and result variables, the latter being the customer's behaviour or opinion resulting from the (experiential) measures. This starting point is based on the stimulus-organism-response model [33], which assumes that a stimulus (e.g., music) in the environment (the station) induces an emotional reaction with the organism (the customer) that is a result of the degree of pleasure (bipolar items, e.g., "unhappy-happy, annoyed-pleased"), arousal (bipolar items, e.g., "relaxed-stimulated, calm-excited") and dominance (sense of control, bipolar items, e.g., "impressionable-influential, obedient-leading"). This emotional reaction subsequently influences the ultimate response: the behaviour of the customer. This behaviour can be approach-oriented (exploring, consuming, recommending), or avoidance-oriented (leaving, complaining, not buying anything) in Fig. 4.

Examples of general opinion and result variables are: general station evaluation (e.g., "your overall opinion of the platform you are waiting on"), recommending station visit to friends, freely purchasing something at this station.

\subsection{Context Variables and Background Questions}

In order to successfully interpret the respondents' answers, the experience instrument also enquires after several of their background characteristics as well as a number of questions relating to the context (actual situation), e.g., age, gender, travel motive, frequency visits to station and the weather.

After the baseline and first measurement, a factor 


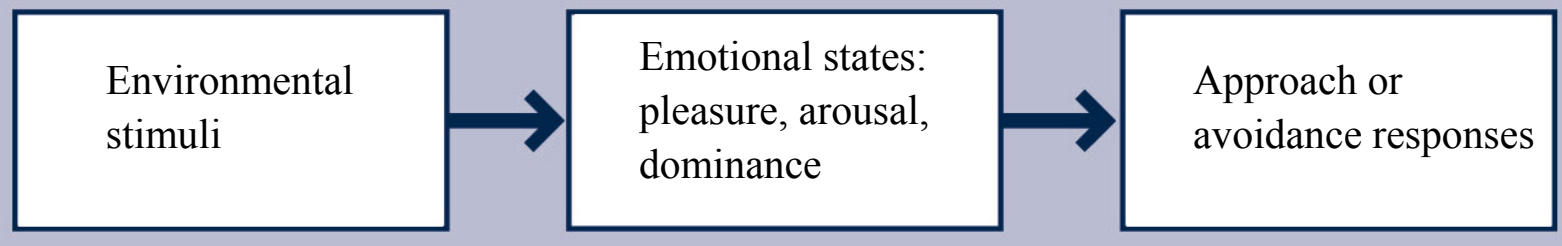

Fig. 4 Stimulus organism and response model [33].

analysis was conducted on the various items with the aim of presenting several related topics which the organization could specifically address. The following six topics were distinguished: attractive (full of atmosphere), inviting, safe, environment, functional and cleanliness:

- attractive: measured with nine items (10-point scale, coefficient Alpha $=0.93)$. Examples of items: attractive, warm aura, pleasing, etc.;

- inviting: measured with 13 items (10-point scale, coefficient Alpha $=0.91)$. Examples: shops/catering, pleasant wait, welcome, etc.;

- safe: measured with five items (10-point scale, coefficient Alpha $=0.85$ ). Examples: safety station, safety platform, lighting, etc.;

- environment: measured with eight items (10-point scale, coefficient Alpha $=0.81)$. Examples: accessibility station, evaluation access transport, evaluation bicycle points/parking, etc.;

- functional: measured with seven items (10-point scale, coefficient Alpha $=0.85$ ). Examples: travel facilities, travel information, flow, etc.;

- cleanliness: measured with five items (10-point scale, coefficient Alpha $=0.80)$. Examples: cleanliness station, cleanliness platform, smell, etc..

\section{Results}

The conventional idea in the railway sector often is that the atmosphere will probably not be highly valued. However, in-depth analysis showed the opposite to be the case. Not only was the (station) atmosphere poorly assessed but it even had the greatest explanatory impact on the general evaluation of the station. The same applied to the presence of commercial facilities and a hospitable welcome, implying that a station with a pleasant and attractive atmosphere, in which passengers can comfortably stay/wait, will attract more passengers who are also (and sooner) prepared to purchase something.

The regression analyses show (Table 2) that the attractiveness of the station in the experience of the customer is the most important quality that needs improvement.

Fig. 5 clearly illustrates the increase in experiential value over time and how the effect of the implemented measures is still holding its own over a year later. If we compare the general evaluation of the themes with the average interest, a priority matrix arises, as visualized in Fig. 6.

Fig. 5 illustrates the passenger's evaluation per theme level as opposed to the relative importance of that theme for the general interest (regression coefficient). The matrix has four quadrants, each with its own priority as regards improvement measures to be taken. Quadrant I (red) has the highest, first priority and Quadrant IV (blue) has the lowest, fourth priority. The importance of each theme is linked to the percentage of respondents that awarded that theme a score of 7 or higher.

As stipulated, the matrix on the left is based on observations during the baseline measurement (Table 2), just as the matrix on the right is based on observations during the 5th measurement. The following conclusions can be drawn:

- The set of improvement measures ultimately has an effect on all themes; 
Table 2 Regression coefficients baseline measurements.

\begin{tabular}{|c|c|c|c|c|c|}
\hline \multirow{2}{*}{ Topics } & \multicolumn{2}{|c|}{ Unstandardized coefficients } & \multirow{2}{*}{$\begin{array}{l}\text { Standardized coefficients } \\
\text { Beta }\end{array}$} & \multirow{2}{*}{$t$} & \multirow{2}{*}{ Sig. } \\
\hline & $B$ & Std. Error & & & \\
\hline Attractive & 0.423 & 0.032 & 0.316 & 13.357 & 0.000 \\
\hline Inviting & 0.065 & 0.023 & 0.052 & 2.845 & 0.005 \\
\hline Functional & 0.172 & 0.043 & 0.181 & 4.026 & 0.000 \\
\hline Safe & 0.244 & 0.038 & 0.269 & 6.452 & 0.000 \\
\hline Environment & 0.067 & 0.021 & 0.060 & 3.229 & 0.001 \\
\hline Cleanliness & 0.133 & 0.031 & 0.129 & 4.251 & 0.000 \\
\hline
\end{tabular}

$B$ : the values for the regression equation for predicting the dependent variable from the independent variable;

Std. Error: these are the coefficients that you would obtain if you standardized all of the variables in the regression, including the dependent and all of the independent variables, and ran the regression. By standardizing the variables before running the regression, you have put all of the variables on the same scale, and you can compare the magnitude of the coefficients to see which one has more of an effect;

Beta: these are the standardized coefficients;

$t$ and Sig.: these are the t-statistics and their associated 2-tailed p-values used in testing whether a given coefficient is significantly different from 0 . Using an alpha of 0.05 , if $t>1.96$, the coefficient is significant different from 0.

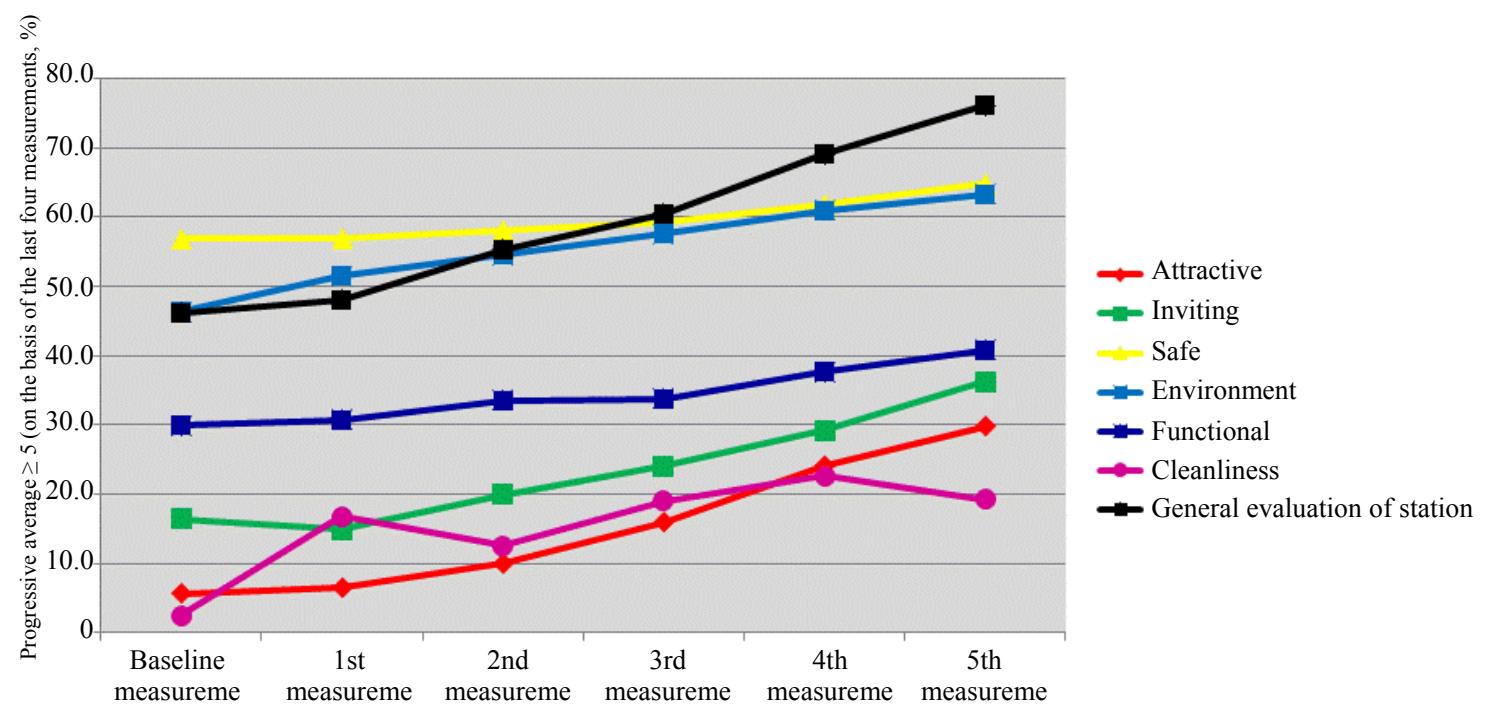

Fig. 5 Progressive average of measurements at Leiden Central Station.

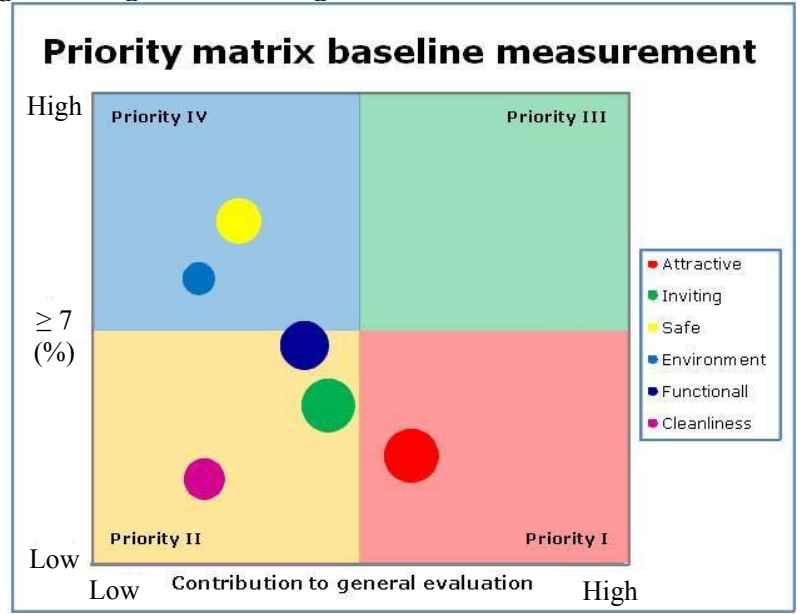

(a)

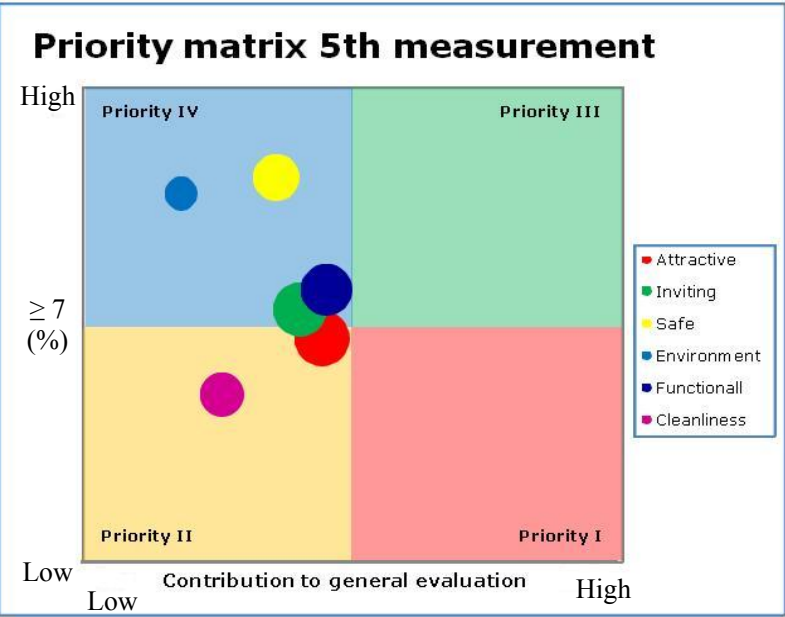

(b)

Fig. 6 (a) Priority matrix themes Leiden Central Station with baseline; (b) 5th measurement. 
- As expected, the themes atmosphere and inviting (both satisfiers) show a relatively large improvement, hence the obvious decrease in relative importance;

- Steering those themes that contribute considerably to the general evaluation and that score badly in the passengers' perception, should be addressed first.

\section{What Has It Yielded to Date?}

At test station Leiden Central, various measures were taken over a period of 3 years that had to result in an improvement of the station perception. At the same time as when these measures were introduced, passengers were regularly asked about their opinion with the station experience monitor. The results showed a clear rise in the station experience on both the six themes and the general station evaluation. In the same period, the score of the general evaluation gradually increased by one whole mark, which is quite an achievement. It is apparent from the intermediate measurements that the steps taken generate the desired effect. If this was not the case, then the instrument offers every possibility to adjust without delay. The results of the analyses confirm that customers perceive the station environment holistically (i.e., in its entirety) [1], but a station is a complex area with fragmented responsibilities. The analyses with the station experience instrument also demonstrate that the direct environment has a strong influence on the station experience when seen from the perspective of the customer. When improving the station experience, the parties involved have an intrinsic inclination to first pay attention to those measures that are directly linked to their personal responsibility. The surplus value of the measurements is not only that implemented steps positively influence the passengers' experience but also that the responsible organizations (ProRail, NS stations, local council) themselves become more aware of the necessity for an integral approach to be able to address and manage the total customer experience.
The modus operandi has yielded a number of significant new insights, such as:

- To positively influence the general station evaluation, the dissatisfiers must be in order first;

- Individual measures often have little impact, whereas combined inter-related packages do afford greater effect and performance;

- In such a case, the "fanning out" of such inter-related packages on experience is often much wider than that could be originally predicted. For example, by working with scent, not only does the station smell better but the experience of cleanliness and safety can also be positively influenced;

- The deployment of satisfiers is a prerequisite for positively influencing the general station evaluation.

\section{Conclusions}

The vision of NS stations implies that the station is translated into four domains and seven worlds, whereby the effects of those measures concurring with that vision are continually measured. In this way, demonstrable and positive effects were found for the (waiting) experience, thus showing the followed strategy to be effective:

- To effectively steer customer experience, a standard measurement instrument that covers a broad spectrum, in terms of both dissatisfaction and satisfaction, is vital. The series of studies demonstrate that the positive influencing of experience, particularly on the basis of satisfiers, generates positive effects;

- Using a standard measurement instrument contributes considerably to generating a lingua franca for measuring experience and predicting future experience-related measures, which should ultimately facilitate an integral approach.

\section{References}

[1] Van Hagen, M. 2011. "Waiting Experience at Train Stations." Dissertation, Eburon, Delft. Accessed September 13, 2012. http://doc.utwente.n1/80061/1/ thesis_M_van_Hagen.pdf. 
[2] Van Hagen, M., Galetzka, M., and Pruyn, A. T. H. 2007. "Perception and Evaluation of Waiting Times of Netherlands Railways (NS)." Presented at European Transport Congress, Noordwijkerhout, the Netherlands.

[3] Muconsult. 2003. De Kwaliteitsbeleving van de Reis Met de Trein. Fase 2: Kwantitatief Onderzoek (Quality Experience of a Train Journey. Phase 2: Quantitative Research (Stated Preference). Netherlands: Internal Publication Netherlands Railways.

[4] Van Hagen, M. 2003. "Belevingswaarde Stations, Inrichting Station en Omgeving Vanuit de Klantwensen (Experience Value of a Train Station, Lay-Out of the Station and Its Surroundings)." Presented at Colloquium Vervoersplanologisch Speurwerk Colloquium Transport Planning, Antwerp, Belgium. (in Dutch)

[5] Wardman, M. 2004. "Public Transport Values of Time." Transport Policy 11: 363-77.

[6] NS. 2006. "NS Visie op Stations. Van Overstapmachine Naar Dynamisch Stadsportaal (NS Vision on Stations: From Transfer Station to a Place to Be)." Accessed March 1, 2006. http://www.spoorbeeld.nl/sites/default/ files/issuu/NS.RetailGids10.LR_.pdf. (in Dutch)

[7] Van Hagen, M., and Peek, G. J. 2006. "Prettiger Reizen Met de Trein. NS-Klantwensenpiramide Is Leidraad Voor Trein-en Stationsomgeving (Pleasure Trip with the Train: NS (Netherlands Railways) Pyramid of Customer Needs for Train and Station Surroundings)." Verkeerskunde (Traffic Magzine) 5 (June): 50-5. (in Dutch)

[8] Van Hagen, M., Peek, G. J., and Kieft, S. 2000. "De Functie van Het Station: Een Visie (The Operation of a Station: A Vision)". Presented at Colloquium Vervoersplanologisch Speurwerk (CVS), Delft. (in Dutch)

[9] Maslow, A. H. 1954. Motivation and Personality. New York: Harper \& Brothers.

[10] Peek, G. J., and van Hagen, M. 2003."What You Want Is What You Should Get: Customer's Wishes in Relation to the Redevelopment of Inner-City Railway Stations Areas." Presented at European Transport Congress, Strasburg, France.

[11] Herzberg, F., Mausner, B., and Snyderman, B. B. 1959. The Motivation to Work, 2nd ed.. New York: John Wiley \& Sons

[12] Wakefield, K. L., and Blodgett, J. G. 1994. "The Importance of Servicescapes in Leisure Service Settings." Journal of Services Marketing 8 (3): 66-76.

[13] Wakefield, K. L., and Blodgett, J. G. 1999. "Customer Response to Intangible and Tangible Service Factors." Psychology and Marketing 16 (1): 51-68.

[14] Johnston, R. 1985. "The Determinants of Service Quality: Satisfiers and Dissatisfiers." International Journal of Industry Management 6: 53-71.
[15] De Bruyn, M., and de Vries, B. 2009. "Het Belang van Kwaliteitsaspecten: Uitdieping van Het Klantwensenonderzoek (The Importance of Quality Aspects: Deepening of Customer Research)." Presented at Colloquium "Oog Voor de Reiziger (Focus on the Traveller)", Driebergen-Zeist, the Netherlands. (in Dutch)

[16] Konijnendijk, T., and van Beek, P. 2008. "Klantoordelen Opnieuw Onderzocht en Gerubriceerd (Customer Scores Researched Again and Classified)." Presented at Colloquium Vervoersplanologisch Speurwerk, Vroeger Was de Toekomst Beter (Colloquium Transport Planning, in the Old Days Everything Seemed to Be Better), Santpoort, the Netherlands. (in Dutch)

[17] Van Beek, P. 2009. "Waardering door de Klant. En dan? (Appreciation by the Customer, and then?)." Presented at Colloquium "Oog Voor de Reiziger (The Station Concept)", Driebergen-Zeist. (in Dutch)

[18] Preston, J., Blainey, S., Wall, G. S., Wardman, M., Chintakayala, P., Heywood, C., et al. 2008. "The Effects of Station Enhancements on Rail Demand." Presented at European Transport Conference, Noordwijkerhout, the Netherlands.

[19] Van Hagen, M. 2009. "How to Meet the Needs of Train Passengers? A Successful Customer Segmentation Model for Public Transport." Presented at European Transport Conference, Noordwijkerhout, the Netherlands.

[20] Van Hagen, M., de Gier, M., and Visser, J. 2005. "De Psychologie van de Treinreiziger: Een Verkenning van de Behoeften en Drijfveren van Treinreizigers (The Psychology of Train Travellers: An Exploration of the Needs and Drivers of Train Travellers)." Presented at Colloquium Vervoersplanologisch Speurwerk, Duurzame Mobiliteit: Hot or Not?, Antwerp. (in Dutch)

[21] NS Poort. 2010.Van Overstapmachine Naar Dynamisch Staatsportaal: Proefstation Leiden (From Transfer Station to a Place to Be: Leiden Experience Station). Malaysia: NS.

[22] Van Hagen, M., and de Munck-Mortier, E. 2003. Je Komt uit Waar je je Thuis Voelt-Belevingswaarde op Stations (You Arrive at the Place Where You Feel at Home-Value of Experience at Stations). NS commercial, internal report. (in Dutch)

[23] Bureau Spoorbouwmeester (Supervisor Design Netherlands Railways). 2011. "Het Stations Concept (The Station Concept)." Accessed September 13, 2012. http://www.spoorbeeld.nl/bureau-spoorbouwmeester/nieu ws/nieuwe-uitgave-van-het-stations-concept. (in Dutch)

[24] Peters, J. 2008. "Meer Licht op Kleur: Een Onderzoek Naar de Invloed van Kleur en Licht op de Stationsbeleving van NS Reiziger (More Light and Colour: A Reserach on the Influence of Colour and Light 
on the Station Experience of Customers of the (NS) Netherlands Railways).” Accessed September 1, 2008. http://www.infrasite.nl/images/railpedia/attachments/802 83049/80446286.pdf. (in Dutch)

[25] Van Hagen, M., Galetzka, M., and Sauren, J. 2010. "Kleur \& Licht op Stations. De Invloed van Kleur en Licht op de Wachttijdbeleving (Colour and Light at Stations. The Influence of Colour and Light on the Waiting Experience)." Presented at Colloquium Vervoersplanologisch Speurwerk, Roermond, the Netherlands. (in Dutch)

[26] Van Hagen, M., Pruyn, A. T. H., Galetzka, M., and Kramer, J. 2009. "Waiting Is Becoming Fun! The Influence of Advertising and Infotainment on the Waiting Experience." Presented at European Transport Conference, Noordwijkerhout, the Netherlands.

[27] Van Hagen, M., Pruyn, A. T. H., Galetzka, M., and Peters , J. 2008. "The Influence of Colour and Light on the Experience and Satisfaction with a Dutch Railway Station. Colour and Light on the Platform: Two Virtual Experiments." Presented at European Transport Conference, Noordwijkerhout, the Netherlands.

[28] Van Hagen, M., Pruyn, A. T. H., Galetzka, M., and
Sauren, J. 2010. "Music at Railway Stations: The Influence of Music on Waiting Experience. Influence of Music Genre on Station and Time Experience at a Virtual Station." Presented at European Transport Conference, Glasgow, UK.

[29] Hof, V. 2008. "Circling Safely: Feeling (Un)Safe at Railway Stations." Master thesis, University of Twente.

[30] Van Hagen, M., and Heiligers, M. 2010. "De Kracht van data. Onderzoek naar Stationsbeleving (The Power of Data. Research on Station Experience)." Presented at Colloquium "Oog Voor de Reiziger (Focus on the Traveller)", Zeist, the Netherlands. (in Dutch)

[31] Van Hagen, M., Boes, E., and van den Heuvel, E. 2009. "Naar een Standaard Belevingsinstrument (Towards a Standardized Experience Measurement Instrument)." Presented at Colloquium "Oog Voor de Reiziger (Focus on the Traveller)", Driebergen, the Netherlands. (in Dutch)

[32] NS. 2010. Van Overstapmachine naar Dynamisch Stadsportaal 2010 (From Transfer Station to a Place to Be 2010). Report NS Poort.

[33] Mehrabian, A., and Russell, J. A. 1974. "An Approach to Environment Psychology. " Journal of Marketing 46 (2): 86-91.

\section{Annex: Objectives and Benefits of a Standard Experience Instrument}

The aim of a standard experience instrument is to render unambiguous insight into the effects of measures taken at stations by carrying out baseline and follow-up measurements. That is to say, prior to any step being taken, the station experience is measured (baseline), and then, several weeks after introduction of the step, another measurement is taken (follow-up). The difference between the two shows the actual benefit. Measurements of different stations will allow stations to be compared with one another (over a certain period) and identify trends and provide insight into structural effects. In turn, this will allow the effects of station measures to be determined and management thereof improved. The standard experience instrument will help to more successfully justify investments and simplify investment decisions.

A uniform way of measurement moreover saves costs for all concerned, because the aim is that the experience instrument can be employed by all parties (NS passengers, NS stations, NS retail, ProRail and, in the future, also regional operators). Besides having a structural learning effect on all of the aforementioned parties, the standard experience instrument will also afford greater understanding and agreement on station quality improvement. As various parties are involved in the instrument's development, a well-founded dialogue has started on what station experience is in the eyes of the customer. All parties are thus becoming increasingly aware that, besides functional aspects also, experiential aspects play a role and that customers' behaviour or evaluation is a result of all the stimuli they pick up in an environment. Of course, the interests of the various parties differ in station projects but their joint focus will increasingly be on the customer's experience of the station. At the moment, the station experience monitor investigates every station in the Netherlands once a year and the 50 biggest stations four times a year. 